\title{
Um Estudo Exploratório na Criação de Fases de Jogos Digitais por Alunos do Ensino Fundamental I
}

\author{
Hugo O. Mesquista ${ }^{1}$, Eduardo H. S. Aranha ${ }^{1}$, Thiago Reis da Silva ${ }^{2}$ \\ ${ }^{1}$ Programa de Pós-Graduação em Sistemas Computacionais - PPgSC \\ Universidade Federal do Rio Grande Norte - UFRN \\ ${ }^{2}$ Instituto Federal de Educação, Ciência e Tecnologia do Maranhão - IFMA \\ Campus São João dos Patos - MA \\ hugohomesquita@gmail.com, eduardoaranha@dimap.ufrn.br, \\ thiago.reisdifma.edu.br
}

\begin{abstract}
This article describes the development of a game that allows students to create their own phases, as well as an exploratory study with twenty-five students. The results indicate its application with elementary students showing the potential of this type of game and its ease of adoption in the classroom, since it does not require programming knowledge to create the phases of the game. The results serve as a basis for new research that can develop tools for creating educational digital games that do not require programming knowledge, but which help the educational process.
\end{abstract}

Resumo. Este artigo descreve o desenvolvimento de um jogo que possibilita ao aluno criar suas próprias fases, além da realização de um estudo exploratório com vinte cinco alunos. Os resultados obtidos indicam sua aplicação com alunos do ensino fundamental mostrando o potencial de engajamento deste tipo de jogo e sua facilidade de adoção em sala de aula, uma vez que não requer conhecimentos de programação para criar as fases do jogo. Os resultados servem de base para novas pesquisas que possam desenvolver ferramentas de criação de jogos digitais educativos que não requerem conhecimentos de programação, mas que auxiliam o processo educacional.

\section{Introdução}

A motivação e o engajamento dos alunos são aspectos importantes no processo de aprendizagem, pois a intensidade do envolvimento exigido para aprender depende dessas características. Uma das formas que pode auxiliar e estimular os alunos são os jogos digitais. Os jogos oferecem uma dinâmica colaborativa e lúdica capaz de estimular habilidades de concentração, motivação, estimulo e engajamento [Shimohara e Sobreira 2015].

A eficácia de se desenvolver o processo de ensino e aprendizagem utilizando os jogos digitais, depende, da participação dos professores e de sua concordância em utilizá-los na educação [Espinosa, Gómez e Hildebrand 2010].

Os jogos digitais estão sendo utilizados na educação, tanto como recursos que aliam a ludicidade a um potencial educativo [Jesus et. al. 2015] quanto como desenvolvimento dos próprios jogos [Silva et. al. 2016]. A ideia de ter alunos da 
educação básica como desenvolvedor dos seus próprios jogos digitais é um campo recorrente de pesquisa. Com as novas formas de integrar as tecnologias para a criação e não apenas consumo, práticas de desenvolvimentos de jogos estão sendo desenvolvidas a fim de expandir o potencial criativo dos alunos para a produção de tecnologias [Shimohara e Sobreira 2015].

E um recurso que vem sendo utilizado para produção de jogos digitais pelos alunos ó o Scratch. O Scratch é uma ferramenta de fácil manuseio e que permite desenvolver jogos com relativa rapidez [Gomes et. al., 2014]. No entanto, existe algumas dificuldades dos alunos e professores do ensino fundamental I desenvolverem jogos mais elaborados com o Scracth, por exemplo, utilizar muitos blocos de comando para realizar algo e o editor de imagens possui poucos recursos para tratamento de imagens, dentre outras.

Este trabalho propõe desenvolver e avaliar um jogo onde o aluno monta a fase, ao invés de programar, como acontece com o Scracth, sendo assim mais simples o desenvolvimento do jogo. Esse processo criativo permite o desenvolvimento de habilidades próprias, favorecendo assim um maior engajamento e motivação do aluno.

Sendo assim, este artigo encontra-se organizado da seguinte maneira: na Seção 2, discutimos a metodologia utilizada. Na Seção 3 abordaremos o jogo desenvolvido, na Seção 4 a avaliação e resultado da aplicação do jogo, enquanto na Seção 5 os trabalhos relacionados. Para finalizar, na Seção 6 apresentamos as considerações finais.

\section{Metodologia utilizada}

O trabalho ora apresentado é um estudo exploratório que investiga a criação de fases de jogos digitais educativos pelos próprios alunos. Este estudo consiste em duas fases: a obtenção de um jogo educacional na qual estudantes criem suas fases e uma avaliação do mesmo em sala de aula.

$\mathrm{Na}$ primeira fase, foi realizada uma pesquisa visando encontrar jogos digitais educativos na qual os estudantes criem suas próprias fases. Como não foram encontrados jogos que atendessem os requisitos (jogos onde os alunos criavam suas próprias fases) desta pesquisa, optou-se pelo desenvolvimento de um jogo novo que tivesse as características requeridas para este estudo. A escolha do jogo a ser desenvolvido foi realizada junto aos professores de uma escola parceira, visando permitir que o jogo fosse executado na mesma de forma alinhada com suas aulas e metodologia pedagógica, além de ter a possibilidade dos próprios alunos criarem, editarem e compartilharem as fases desenvolvidas.

Desta forma, os autores desta pesquisa desenvolveram o jogo com os requisitos pedagógicos identificados pelos professores e aplicaram o jogo (segunda fase do estudo) na escola. Para o planejamento deste estudo e descrição dos resultados, os autores seguiram as orientações propostas em Wohlin et. al. (2000). Para guiar o planejamento e execução do estudo, foram definidas três Questões de Pesquisas (QP). A partir das QP, três Hipóteses de Pesquisa (HP) foram definidas, são elas:

- QP1: Quais as dificuldades reportadas ou observadas que os alunos tiveram ao jogar ou criar fases do jogo sem maiores treinamentos?

- HP1: Nenhuma dificuldade relevante, pois o jogo não requer treinamento específico nem conhecimentos de programação por parte dos alunos. 
VI Congresso Brasileiro de Informática na Educação (CBIE 2017)

Anais do XXIII Workshop de Informática na Escola (WIE 2017)

- QP2: Os alunos se sentiram motivados em criar jogos?

- HP2: Sim, mesmo que simples, as fases de jogo desenvolvidas atraem o interesse do aluno pelo fato deles serem os protagonistas desse processo criativo.

- QP3: Os alunos se interessaram por compartilhar seus jogos e jogar os de seus colegas?

- HP3: Sim, compartilhar seus jogos e jogar os dos demais colegas engajam os alunos.

- QP4: Quantas fases cada aluno conseguiu criar e jogar no período de $1 \mathrm{~h}$ ?

- HP4: Pelo menos duas fases, além de jogar a de seus colegas, pois as atividades baseadas em jogos podem ser realizadas em laboratório no horário regular de aula (45min a $1 \mathrm{~h})$.

Estas hipóteses, uma vez confirmadas, demonstram o impacto potencial e facilidade de adoção que jogos como o do tipo investigado neste trabalho podem ter em sala de aula.

\section{Jogo Desenvolvido}

O jogo Localização foi idealizado a partir de atividades realizadas no ensino fundamental por uma escola na qual os autores do trabalho possuem parceria. Essas atividades tratam de conceitos matemáticos de localização espacial de objetos a partir de um ponto de referência (à esquerda de, à direita de, abaixo de, entre outros). A escolha desse jogo se deu pelo fato de se ter embasamento pedagógico, de poder ser implementado como um jogo de plataforma (estilo atrativo), e pelo tema ser relevante para realização de um estudo na escola parceira.

No jogo proposto, o aluno pode tanto jogar fases como criar e compartilhar novas fases para este jogo. Para isto, turmas, professores e alunos são cadastrados previamente no sistema servidor do jogo. Após entrar com seu login e senha no jogo, o aluno é direcionado para a tela de visualização de fases, a qual permite que o aluno visualize as fases do jogo criadas por seu professor (área A da Figura 1), as fases criadas por ele (B) e as fases criadas por seus amigos (C). Para jogar uma fase, basta selecionála e clicar no botão de play irá aparecer. Já na área B da tela existe um botão que permite a criação de uma nova fase com cenário vazio.

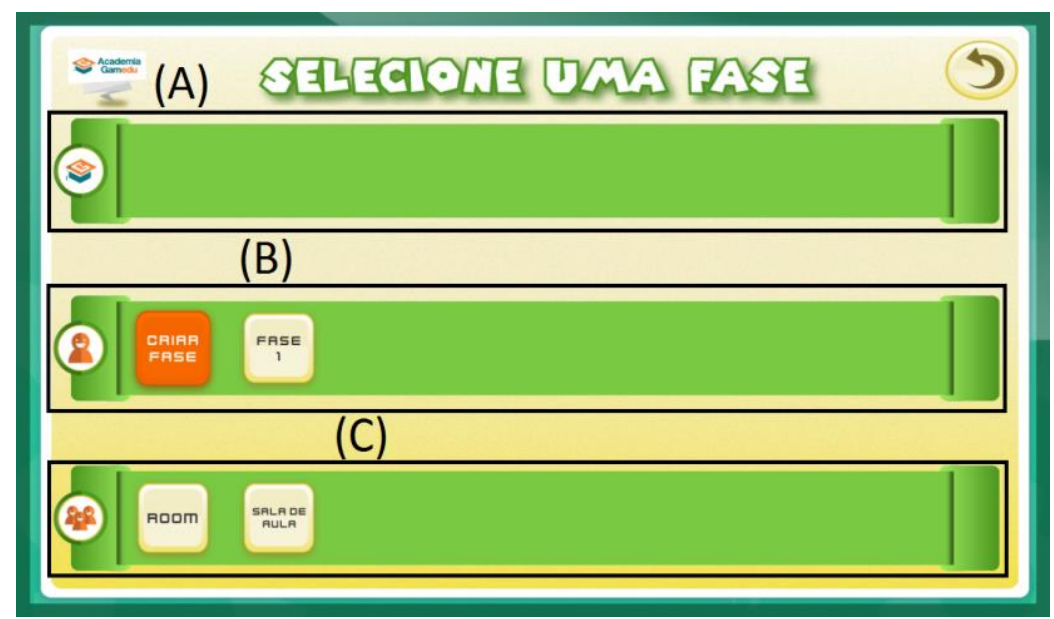

Figura 1. Tela de lis tagem de fases. 
VI Congresso Brasileiro de Informática na Educação (CBIE 2017)

Anais do XXIII Workshop de Informática na Escola (WIE 2017)

O jogo é composto ainda por mais dois módulos: o Módulo de Execução, responsável pela execução de uma fase; e o Módulo de Edição, que através de uma interface intuitiva possibilita ao aluno criar ou editar suas fases. As próximas subseções detalham esses dois módulos do jogo.

\subsection{Módulo de Execução}

Ao se clicar para jogar uma fase do jogo, a mesma começa exibindo uma dica de onde uma chave perdida se encontra. O texto da dica é definido durante o processo de criação da fase e, no caso do exemplo ilustrado na Figura 2, possui informações de localização a partir de dois pontos de referência.

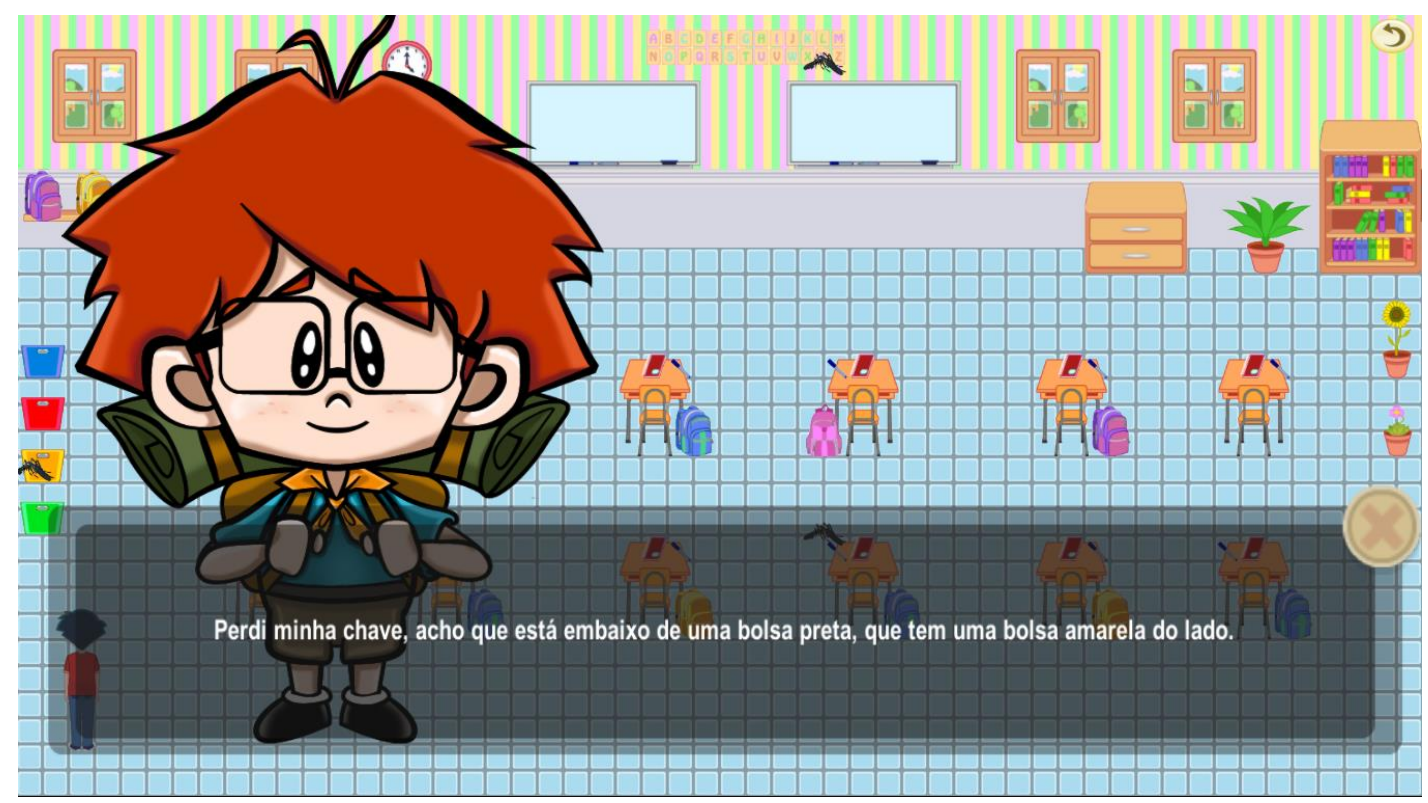

Figura 2. Tela de início de fase, mos trando dica de onde se encontra a chave perdida.

Após a exibição da dica, o aluno deve movimentar o personagem do jogo em busca da chave levando em consideração a dica que foi dada.

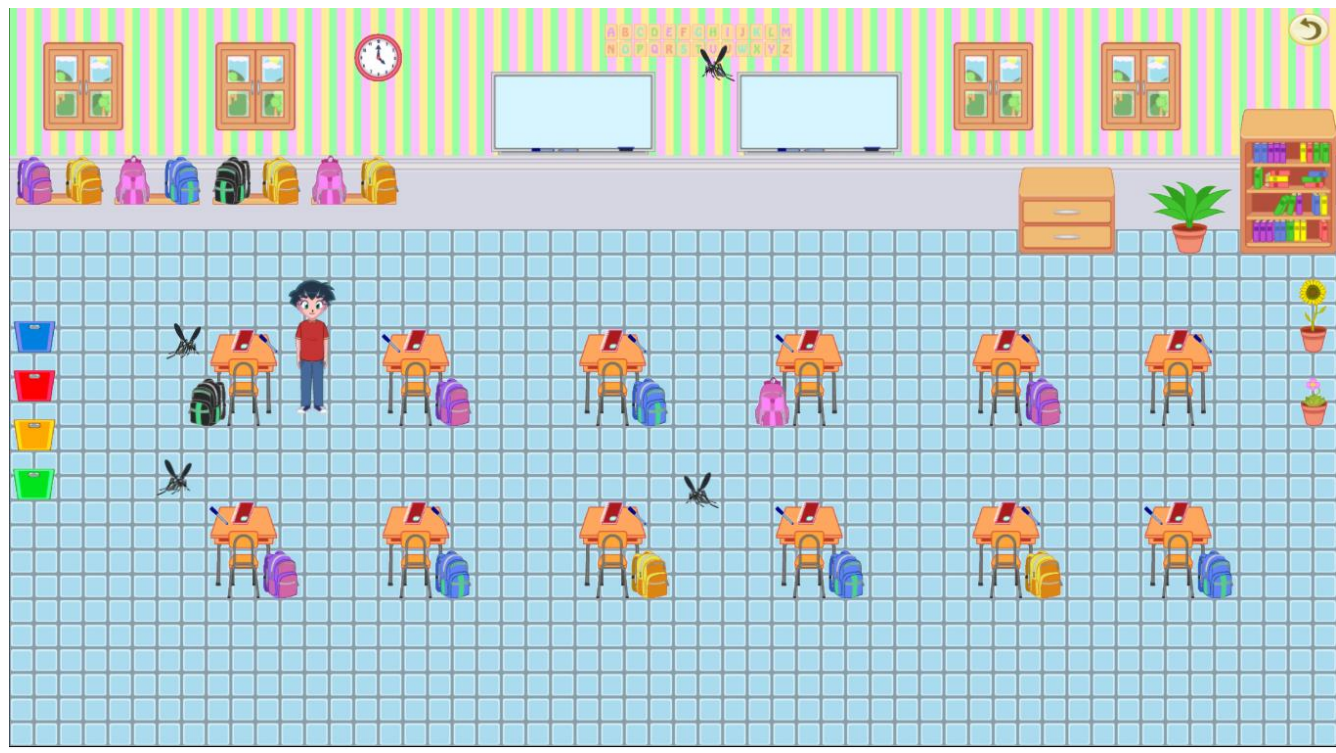

Figura 3. Exemplo de fase criada no jogo Localização.

O cenário da fase é montado pelo aluno e, no caso da Figura 3, simula um ambiente de uma sala de aula. Visando possibilitar diferentes níveis de dificuldade, o 
aluno pode: (i) usar diferentes tipos de objetos como ponto de referência; (ii) colocar objetos como obstáculos, como as cadeiras que o personagem precisa contornar para poder se movimentar; (iii) colocar inimigos, como insetos que os alunos devem evitar para obter a pontuação máxima na fase. No caso, esses insetos se movimentam em direção ao avatar, através de um algoritmo de busca de caminho.

A fase é concluída quando o aluno encontra a chave perdida. Para isso, basta posicionar o personagem no local onde a chave se encontra escondida, o qual é indicado pela dica, e então pressionar a tecla P. Em seguida, é exibida a pontuação atingida pelo aluno, representada através de estrelas (Figura 4). Se não houver colisão com insetos nem tentativas erradas de se encontrar a chave, a pontuação máxima é atingida. Caso contrário, sua pontuação será reduzida de acordo com a quantidade de colisões ou tentativas frustradas de se encontrar a chave.

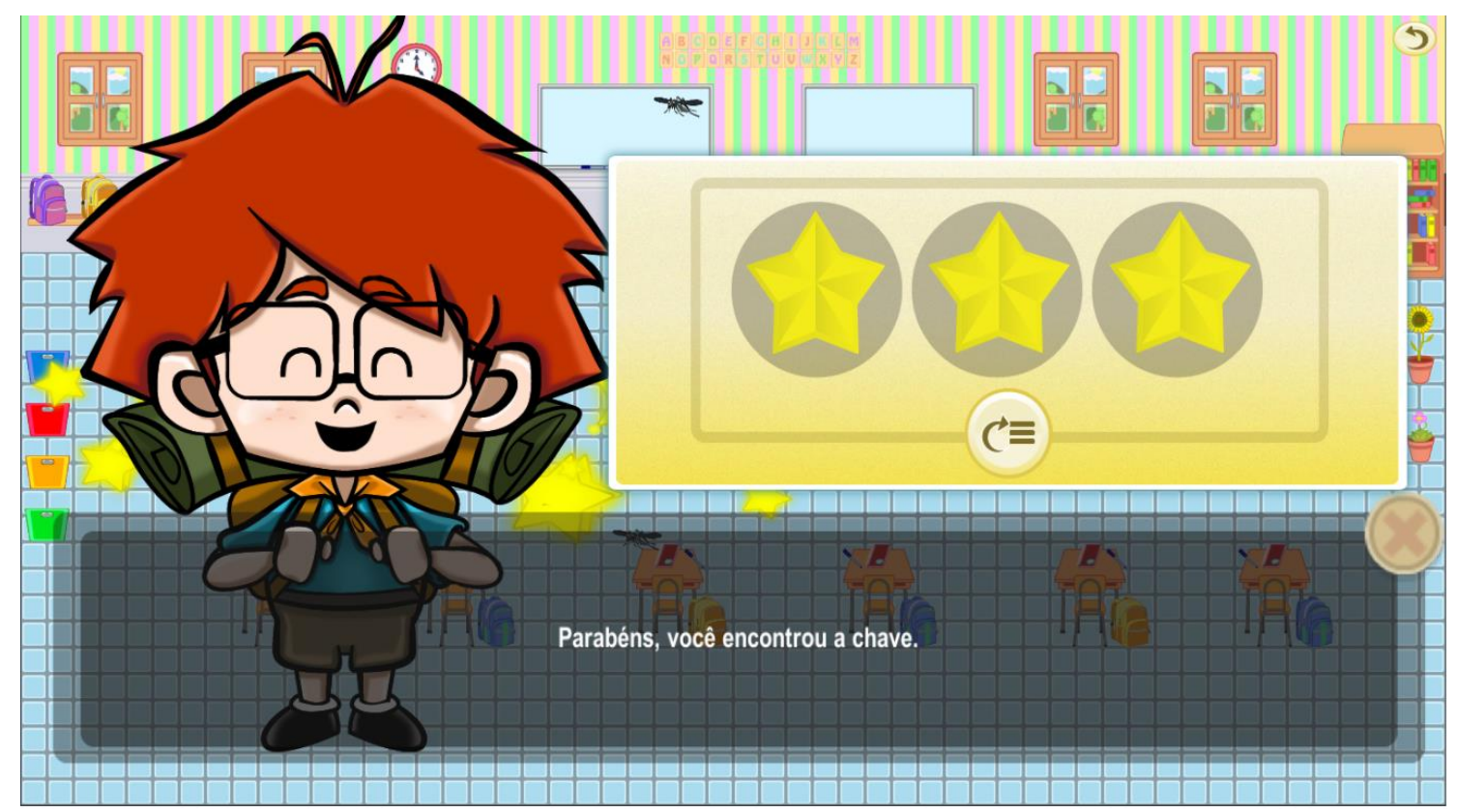

Figura 4. Fim de fase de jogo, com avaliação de desempenho do aluno.

\subsection{Módulo de Edição}

$\mathrm{O}$ módulo de edição de fase permite que o aluno crie ou altere uma fase do jogo. $\mathrm{O}$ processo de criação de uma fase consiste na inserção de objetos no cenário provindos de uma biblioteca disponível no jogo. Ao abrir o módulo de edição, o cenário se encontra vazio, tendo apenas os componentes essenciais do jogo, o personagem e a chave perdida. Esta chave fica visível apenas no modo de edição de fase, não no modo de execução.

Internamente, o módulo de edição é subdividido em três componentes principais (ver Figura 5). O primeiro componente é usado para a Seleção de Objetos (A), no qual os objetos para serem colocados no cenário são apresentados e organizados em categorias de objetos (piso, parede, mobília, entre outros). O segundo componente é a Barra de Ferramentas (B), uma caixa de ferramentas que serão utilizadas para a edição do jogo (inserir componentes, apagar componentes, salvar fase, dentre outros). Por fim, o terceiro componente do módulo de edição é o Cenário (C), área do jogo na qual são colocados os objetos. 
VI Congresso Brasileiro de Informática na Educação (CBIE 2017)

Anais do XXIII Workshop de Informática na Escola (WIE 2017)

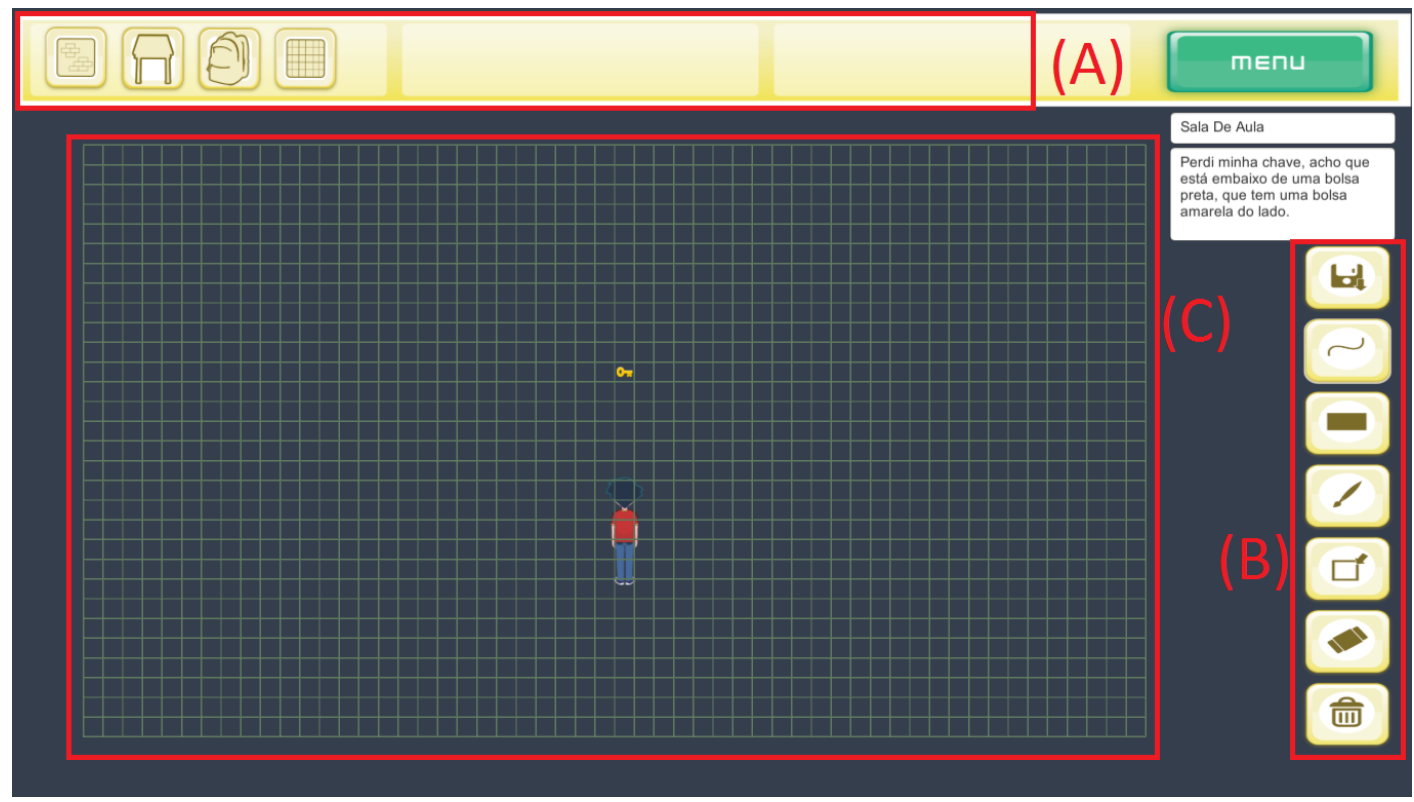

Figura 5. Tela de criação de nova fase.

No módulo de edição também é necessário que o aluno defina qual o local onde o avatar que será controlado pelo aluno deve se encontrar inicialmente, especificar o local onde a chave perdida se encontra e escrever uma dica para que os jogadores consigam encontrar a chave. Vale ressaltar que processo de edição de uma fase é semelhante ao de criação de uma nova, e que ao editar ou criar uma nova fase o contexto educacional deve mantido pelo aluno, sendo responsabilidade do professor verificar este aspecto. A Figura 6 ilustra uma fase criada no módulo de edição.

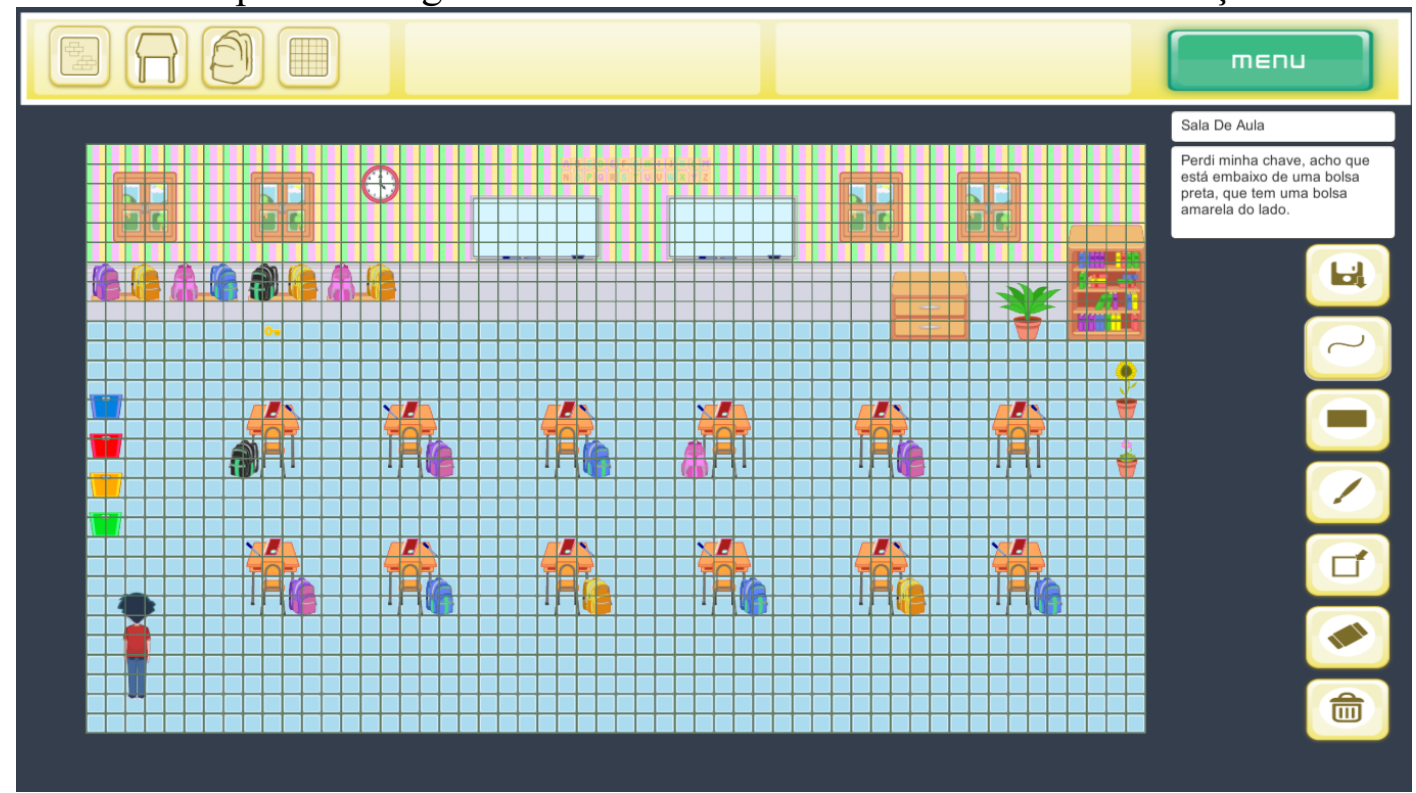

Figura 6. Módulo de edição.

\subsection{Arquitetura desenvolvida}

A arquitetura utilizada no jogo Localização foi elaborada com o objetivo de servir de protótipo e que pudesse ser estendida posteriormente para novos jogos. A arquitetura utilizada foi dividida em duas partes. A primeira é o Front-End, responsável por executar o jogo, carregar dados pertinentes do aluno e do jogo. A segunda é o Back-End que, de maneira geral, é responsável por armazenar e compartilhar os dados e fases criadas pelos alunos. 
VI Congresso Brasileiro de Informática na Educação (CBIE 2017)

Anais do XXIII Workshop de Informática na Escola (WIE 2017)

A comunicação entre o Front-End e o Back-End, é feita através de uma Application Programming Interface Representational State Transfer (API REST) disponibilizada pelo Back-End. É ilustrado na Figura 7, a arquitetura desenvolvida.

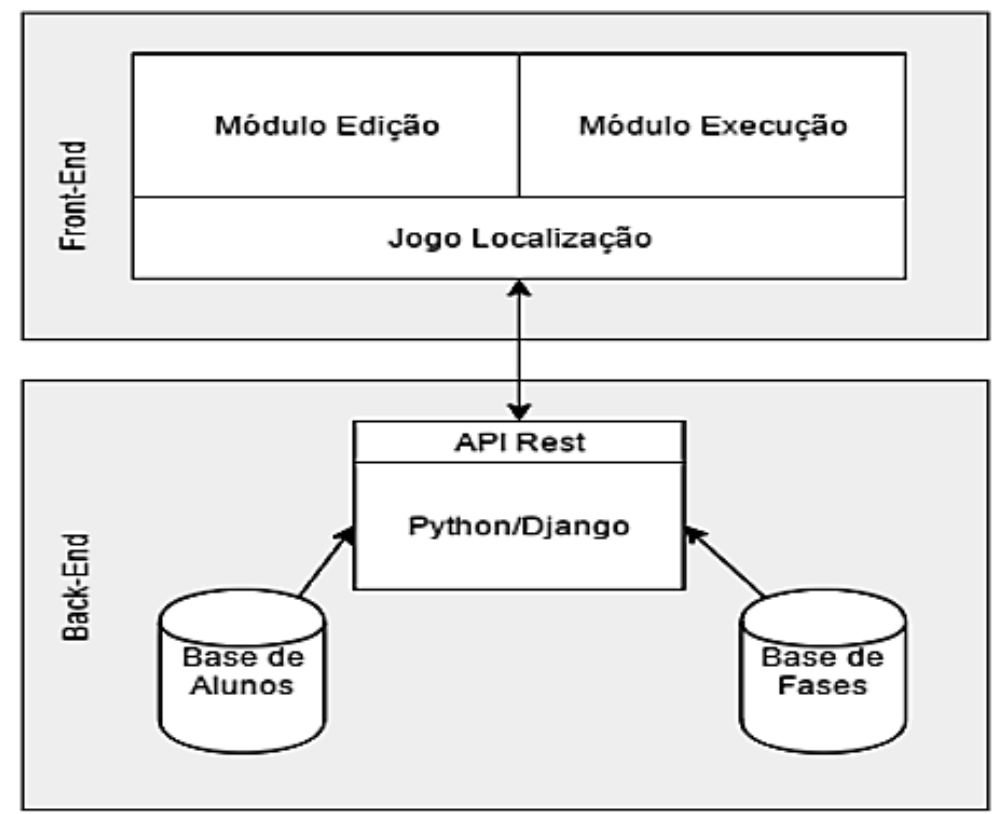

Figura 7. Arquitetura des envolvida.

\section{Avaliação do Jogo}

Esta seção detalha uma avaliação realizada em sala de aula com o jogo Localização, visando responder as questões de pesquisa deste estudo exploratório.

\subsection{Participantes}

O jogo proposto foi aplicado em dois ambientes distintos. Em um primeiro momento, o jogo foi aplicado junto a uma turma de 17 alunos entre 7 e 9 anos, em um horário de aula de alunos envolvidos no tempo integral. Em um segundo momento, o jogo foi aplicado junto a alunos que estavam iniciando em um clube de programação de jogos digitais realizados no último horário de aula, sem ser no contraturno. Ao todo, oito alunos deste clube participaram do estudo, com idades entre 9 anos e 11 anos.

\subsection{Coleta de dados}

Neste estudo de caso, foram coletados os seguintes dados dos participantes:

- Anotações sobre o comportamento, questionamentos e dificuldades dos alunos durante a realização das atividades;

- Respostas aos questionamentos feitos pelo tutor aos alunos, com perguntas sobre o que cada um achou de interessante, o que poderia melhorar, dentre outras. Apenas alunos do segundo momento (clube) responderam a esses questionamentos, devido à baixa idade dos participantes do primeiro momento.

\subsection{Procedimentos de execução}

Durante o estudo, o professor da aula realizou alguns procedimentos. Primeiro, ele demonstrou rapidamente aos alunos o funcionamento do jogo. Em seguida, foi solicitado que os alunos jogassem quatro fases criadas previamente pelo tutor. Após 
VI Congresso Brasileiro de Informática na Educação (CBIE 2017)

Anais do XXIII Workshop de Informática na Escola (WIE 2017)

isso, os alunos puderam criar suas próprias fases e jogá-las, como também as fases dos outros alunos presentes. Para finalizar, cada aluno foi interrogado acerca das qualidades e dificuldades da ferramenta.

\subsection{Resultados}

Esta seção tem por finalidade discutir os resultados da execução do estudo, respondendo a cada uma das questões de pesquisa.

\section{QP1: Quais as dificuldades reportadas ou observadas que os alunos tiveram ao jogar ou criar fases do jogo sem maiores treinamentos?}

De acordo com dados coletados pelo tutor durante o estudo, foi constatado que todos os alunos após receberem uma explicação de como criar fases para o jogo, conseguiram criar novas fases sozinhos. As dúvidas que os alunos tiveram foram sanadas durante a explicação e no momento da criação das fases eles não apresentaram novas dúvidas acerca de como criar novos jogos. Esse resultado suportam a Hipótese HP1: "Nenhuma dificuldade relevante, pois o jogo não requer treinamento específico nem conhecimentos de programação por parte dos alunos".

\section{QP2: Os alunos se sentiram motivados em criar fases?}

Conforme os resultados do estudo realizado, podemos perceber que a houve motivação por parte de todos os alunos para a criação das fases, tendo afirmado que gostaram e acharam divertido o processo de criação. Uma observação reportada foi a de uma estudante que não tinha interesse em jogar jogos educativos, mas que demonstrou grande interesse quando a ideia passou ao jogo ser criado por ela.

Uma ressalva foi feita por dois alunos que embora tenham dito que se sentiram motivados, estes relataram que gostariam de mais variedades de jogos para melhorar as suas experiências em relação à ferramenta.

Dois fatores foram relevantes em relação à motivação, sendo estes a quantidade de objetos e a pontuação após jogar a fase. Em relação aos objetos, todos afirmaram que gostariam que mais objetos fossem disponibilizados para serem utilizados durante a criação da fase. $\mathrm{O}$ outro fator foi constatado pelo professor que os alunos se sentiam motivados a jogar mais vezes a mesma fase com o objetivo de obter uma pontuação maior.

Os resultados reportados suportam a nossa Hipótese HP2: "Sim, mesmo que simples, as fases de jogo desenvolvidas atraem o interesse do aluno pelo fato deles serem os protagonistas desse processo criativo".

QP3: Os alunos se interessaram por compartilhar suas fases e jogar as de seus colegas?

Conforme os dados coletados, foi constatado o interesse por parte dos alunos em compartilhar as fases que estavam sendo desenvolvidos com os outros participantes. $\mathrm{O}$ tutor relatou que todos os alunos, após criarem uma fase, pediam para que os outros participantes a jogasse. Diante disso, os resultados dessa QP confirmam a Hipótese HP3: "Sim, compartilhar seus jogos e jogar os dos demais colegas engajam os alunos".

\section{QP4: Quantas fases cada aluno conseguiu criar e jogar no período de $1 \mathrm{~h}$ ?}

Durante o estudo foi possível perceber que o período de aula de cinquenta minutos foi suficiente para cada aluno criar em média de 3 a 4 fases, jogá-las e jogar a fases que 
vinham no jogo e as criadas por seus colegas. Esse resultado confirma a Hipótese HP4: "Pelo menos duas fases, além de jogar a de seus colegas, pois as atividades baseadas em jogos podem ser realizadas em laboratório no horário regular de aula (45min a $1 \mathrm{~h}$ ) ".

\subsection{Ameaças à Validade}

Entre os fatores que ameaçam a validade deste estudo, destaca-se o impacto na generalização dos resultados, dada a pequena quantidade de participantes. No entanto, como o objetivo deste estudo foi mais exploratório, os resultados demonstram que o jogo foi avaliado positivamente e que os objetivos instrucionais foram alcançados facilmente, gerando evidências que suportam os princípios básicos deste trabalho e que fomentam a realização de estudos adicionais com propostas e evidências mais generalizáveis acerca do tema investigado neste trabalho.

Além disso, o professor de ambas as turmas nas quais o jogo foi aplicado tinham conhecimentos de programação. Com isto, mais estudos são necessários para se saber da dificuldade de uso desta ferramenta por parte de professores sem conhecimentos de programação. Entretanto, em uma reunião com professores do ensino fundamental I, o jogo foi apresentado e eles conseguiram jogar sem maiores dificuldades, após uma breve explicação do funcionamento do jogo. Isto sugere que o jogo na maneira na qual foi desenvolvida também é de fácil uso por parte dos professores.

\section{Trabalhos Relacionados}

Estudos envolvendo alunos da educação básica desenvolvendo seus próprios jogos já foram reportados por outros pesquisadores. Shimohara e Sobreira (2015) descreve os resultados desenvolvido em uma instituição escolar, com 4 turmas do $5^{\circ}$ ano do ensino fundamental I, cujos alunos desenvolveram jogos digitais com a ferramenta Scracth com desafios de matemática, aliando o poder motivador dos jogos à criação de desafios. Rodriguez et. al. (2015) apresenta a experiência vivenciada em um projeto, cujo objetivo principal foi desenvolver noções básicas do pensamento computacional, com alunos do primeiro ano do ensino médio com desenvolvimento de jogos por meio dos recursos do Scratch. Andrade et al. (2013) também utilizam o Scratch, mas para desenvolver jogos e ensinar matemática para crianças de séries iniciais.

O estudo aqui apresentado diferencia-se dos demais nos seguintes pontos. Primeiro, o foco do nosso trabalho é o engajamento dos alunos no assunto escolar, não tanto no ensino de pensamento computacional. O segundo ponto é que no jogo produzido não é preciso programar utilizando blocos, como no Scracth. O objetivo é que os alunos criem fases de jogos apenas arrastando os elementos disponíveis no jogo, sem a necessidade de fazer uma programação para essa determinada funcionalidade. Com isto, é possível aumentar a utilização de jogos digitais em sala de aula por parte dos professores e alunos do ensino fundamental.

\section{Considerações finais}

O uso dos jogos digitais vem aumentando na educação, tanto como recursos que aliam a ludicidade a um potencial educativo, quanto como parte do processo de aprendizagem dos próprios jogos que podem criar seus próprios jogos. Vários estudos vêm apresentando o uso do Scratch e de outras ferramentas para criação de jogos, mas que 
VI Congresso Brasileiro de Informática na Educação (CBIE 2017)

Anais do XXIII Workshop de Informática na Escola (WIE 2017)

muitas vezes encontram barreiras de uso por falta de capacitação dos alunos e professores.

Este trabalho investigou a criação de fases de jogos educativos pelos próprios alunos, sem a necessidade de conhecimentos prévios de programação. Para isto, foi necessária a criação de um jogo baseado em atividades pedagógicas realizadas pelos professores de uma escola. Sua aplicação com alunos do ensino fundamental mostrou o potencial de engajamento deste tipo de jogo e sua facilidade de adoção em sala de aula, uma vez que não requer conhecimentos de programação. Este resultado serve de base para novas pesquisas que possam desenvolver ferramentas de criação de jogos digitais educativos mais genéricas, que não requerem conhecimentos de programação, mas que auxiliam o processo educacional através de um aumento do engajamento dos estudantes nos temas estudados na escola e no processo criativo de elaboração de fases de jogos.

\section{Referências}

Andrade, M.; Silva, C.; Oliveira, T. (2013) "Desenvolvendo Games e Aprendendo Matemática Utilizando o Scratch". In: Simpósio Brasileiro de Jogos e Entretenimento Digital - SBGAMES.

Espinosa, R. S. C.; Gómez, J. L. E.; Hildebrand, H. R. (2015) "Aprendizagem baseada em Jogos Digitais". In: XIV Simpósio Brasileiro de Jogos e Entretenimento Digital SBGAMES, p.204-210.

Gomes, W. F.; Louzada, C. S.; Nunes, M. A. S. N.; Salgueiro, E. M.; Andrade, B. T. (2014) "Incentivando meninas do ensino médio à área de Ciência da Computação usando o Scratch como ferramenta”. In: XX Workshop de Informática na Escola WIE, p.223-232.

Jesus, Â. M.; Gonçalves, D. A. S.; Almeida, L.; Ferreira, C. (2014) "Aplicação de Desenvolvimento de Jogos Digitais como um Meio de Motivação em Diferentes Níveis de Ensino de Computação”. In: XX Workshop de Informática na Escola WIE, p.56-65.

Rodriguez, C. L.; Lopes, A. M. Z.; Marques, L.; Isotani, S. (2015) "Pensamento Computacional: transformando ideias em jogos digitais usando o Scratch". In: XXI Workshop de Informática na Escola - WIE, p.62-71.

Shimohara, C.; Sobreira, E. S. R. (2015) "Criando Jogos Digitais para a aprendizagem de matemática no ensino fundamental I'. In: XXI Workshop de Informática na Escola - WIE, p72-81.

Silva, T. R.; Aranha, E. H. S.; Santos, F. G.; Tavares, K. F. (2016) "Um Relato de Experiência da Aplicação de Videoaulas de Programação de Jogos Digitais para Alunos da Educação Básica”. In: XXII Workshop de Informática na Escola - WIE, p.141-150.

Wohlin, C.; Runeson, P.; Host, M.; Ohlsson, C.; Regnell, B.; Wesslén, A. (2000) "Experimentation in Software Engineering: an Introduction". Kluver Academic Publishers. 